NASA Technical Memorandum 102346

\title{
The Effect of Electrode Configuration on Arcjet Performance
}

Frank M. Curran

National Aeronautics and Space Administration

Lewis Research Center

Cleveland, Ohio

and

David H. Manzella

Sverdrup Technology, Inc.

NASA Lewis Research Center Group

Cleveland, Ohio

Prepared for the

25th Joint Propulsion Conference

cosponsored by the AIAA, ASME, SAE, and ASEE

Monterey, California, July 10-12, 1989

\section{N/SA}


.

" 


\title{
THE EFFECT OF ELECTRODE CONFIGURATION ON ARCJET PERFORMANCE
}

\author{
Frank M. Curran \\ National Aeronautics and Space Administration \\ Lewis Research Center \\ Cleveland, Ohio 44135 \\ and \\ David H. Manzella \\ Sverdrup Technology, Inc. \\ NASA Lewis Research Center Group \\ Cleveland, Ohio 44135
}

\begin{abstract}
A radiation cooled, segmented anode was tested in a low power ( $1 \mathrm{~kW}$ class) arcjet thruster in order to study the current distribution in the attachment region of the nozzle of the thruster. The nozzle was composed of five segments insulated from one another with boron nitride spacers and matched the critical dimensions of nozzles commonly used in previous testing. The anode was configured so that the current could be collected across any combination of the segments and the potential difference between the cathode and each of the segments was monitored during testing.

Test measurements showed that the discharge initiates in the high pressure region of the nozzle upstream of the diverging section of the nozzle and then rapidly moves to seat in the diverging section. In stcady state operation, with all of the segments connected, the current was observed to attach diffusely across the four segments in the divergent section. Virtually no current was collected by the upstream segment that included both the converging section and constrictor. The arcjet operated stably as segments were switched out to force the anode attachment zone downstream in the nozzle. In the case in which only the final segment was conducting, floating potential measurements from the other segments provided an approximation of the voltage gradient along the arc column. This showed that more than 50 percent of the energy input to the device is added to the propellant downstream of the constrictor exit. Floating potential measurements also provided a rough indication of the anode fall voltage. This appeared to be between 10 and 20 volts when the arcjet was operating with the two downstream segments isolated, but increased greatly (to more than 40 volts) when the current was forced to the high pressure region of the constrictor.
\end{abstract}

\section{INTRODUCTION}

Over the past 5 years a research and development effort has been focused on readying $\mathrm{kW}$ class, dc arcjet thruster technology for north-south stationkeeping (NSSK) of geosynchronous communications satellites. These programs have demonstrated stable arcjet operation on storable propellants over the range of specific power available on next generation spacecraft. ${ }^{1-4}$ Specific impulse values in the range of 450 to 550 seconds have been demonstrated. This represents at least a 50 percent increase over that available with the propulsion systems currently in use. In the course of these investigations, a pulse width modulated power supply with an integrated induction energy storage pulser for startup has been developed 5 . Starting phenomena have been studied in detail and found to be dependent on several factors including pulse rise time, mass flow rate, and arcjet geometry. 6 A $1000 \mathrm{hr} / 500$ cycle lifetest of a laboratory model thruster was completed ${ }^{7}$ and flighttype systems have been built for life, performance, and satellite integration testing. 8,9 Langmuir probe surveys of the plume have measured electron number density and temperature distributions in the plume far field 10,11 and these data have been used in a preliminary assessment of plume impacts on communications. 12

In addition to the technology development effort, basic research on fundamentals controlling both electrode life and device efficiency is also in progress. While the emission processes and electrode erosion phenomena have been studied in some detail $3,13,14$ little is known about the fundamental energy input mechanism which is the major efficiency driver in the device. In the arcjet, an arc is struck between a tipped cathode and an anode which also functions as the nozzle. Efficiency is determined by energy losses at the electrodes; losses due to excitation, ionization, and dissociation of the gas not recovered in the expansion process (i.e., frozen flow losses); and incompletc expansion in the nozzle. The emission processes at the cathode has bcen well documented ${ }^{14}$ and represent small energy losses which probably cannot be altered significantly. Similarly, a recent report has shown 
that constrictor tip geometry and roughness have little effect on performance. ${ }^{15}$ The same study indicated, however, that the design of the diverging section of the nozzle had a significant impact on the operating characteristics of the device. This is because the nozzle geometry is important in determining the region in which the arc attaches. Little is known about this region because the small size of the device makes both intrusive and non-intrusive diagnostics difficult.

This report describes preliminary results of an experimental program designed to improve the understanding of the arc anode attachment zone and the effect it has on arcjet operating conditions. A fivesegmented anode/nozzle was fabricated and run in a laboratory model arcjet. This nozzle had the same critical dimensions as the baseline nozzle used in previous laboratory experiments, but the five segments allowed observation of the current distribution from the constrictor through the diverging section of the nozzle. The design permitted these segments to be isolated individually or in groups, and measurement of the potential difference between the cathode and any of the individual segments was possible. The arcjet was run on a hydrogen/nitrogen mixture simulating the decomposition products of hydrazine at a mass flow rate and power level typical of that expected on a communications satellite.

\section{APPARATUS AND EXPERIMENTAL PROCEDURE}

Arcjet Thruster. A cross-sectional schematic of the arcjet thruster used for this report is shown in Figure 1. This modular thruster is identical to the thrusters used in many recent tests ${ }^{14,15}$ with the exception of the minor modifications made to accomodate the segmented nozzle and the nozzle itself.

The cathode was made from a 2 percent thoriated tungsten rod $3.2 \mathrm{~mm}$ in diameter and approximately $190 \mathrm{~mm}$ in length. The cathode tip was initially ground to a $30^{\circ}$ half angle to match the converging side of the first segment of the nozzle. The cathode entered the rear insulator via a modified stainless steel compression type fitting. This fitting was held in place by a threaded, center-drilled, holding bolt and which also locked the cathode into place. A graphite foil gasket was inserted between the compression fitting and the rear insulator to provide a gas-tight scal.

Propellant entered the thruster through a threaded fitting that seated on a graphite foil gasket on the rear insulator and mated with a side-tapped, centerdrilled stainless steel anchor. The inner diameter of this anchor was large enough to add one passage of an aluminum tube through which the cathode passed.
This effectively isolated the propellant system from the arcjet electrodes.

The rear insulator was made of high purity boron nitride and held an inconel spring and a boron nitride compression plunger. Stainless steel washers were inserted behind and in front of the spring as necessary to give the desired length. A stainless steel anode housing was used in this test. The forward (downstream) surface of this housing was thinned down to the point that the first anode scgment (comprising the converging side of the nozzle and the constrictor) extended slightly from the end. The housing also held the boron nitride front insulator and the propellant injection disk. Graphite foil gaskets were inserted between the components. The front insulator also served to center the cathode in the arc chamber and rectangular slots along its exterior allowed propellant passage to the injection disk. Tangential injection ports, $2 \mathrm{~mm}$ in diameter, in this disk provided propellant swirl for anc stabilization.

The rear insulator and anode housing were clamped together by two stainless steel flanges connected by four bolts. Tolerances were such that, when the thruster was assembled, the spring forced compression of the seals between the critical components so as to maximize swirl strength. The front flange was modified to accept four sets of insulated feedthroughs which, in turn, supported four additional bolts to clamp the anode segments and insulators together as described below.

Segmented Anode/Nozzle A cross-sectional schematic of the anode/nozzle is shown in Figure 2(a). As mentioned previously, the upstream segment comprised the converging side of the nozzle and the constrictor. This segment was made of 2 percent thoriated tungsten. The converging side of the nozzle had a $30^{\circ}$ half-angle and the constrictor was, nominally, $0.64 \mathrm{~mm}$ in diameter and $0.25 \mathrm{~mm}$ in length. Because of difficulty encountered in fabrication, each of the next three segments were made from molybdenum rather than thoriated tungsten. A more detailed schematic of these segments is shown in Figure 2(b). Each segment was $1.27 \mathrm{~mm}$ wide near the interior surface of the nozzle. A step was cut in each to allow stacking with the boron nitride insulator disks, shown in Figure 2(c). At the interior surface of the nozzle, the boron nitride spacer was $0.25 \mathrm{~mm}$ wide. Each of the molybdenum segments also was fabricated with a tab designed to accept a slip-on electrical connector. The final anode segment was made from 2 percent thoriated tungsten and machined to accept a stainless stcel clamping flange designed to connect to the forward flange on the anode housing. The unassembled components are shown in Figure 3(a), and the assembled anode nozzle is shown in Figure $3(\mathrm{~b})$. When assembied, the nozzle had a $20^{\circ}$ half angle in the diverging section of the nozzle and an 
area ratio of 225 . These dimensions are identical to those baselined for other tests. ${ }^{14,15}$

Electrical Configuration. A simplified electrical schematic is shown in Figure 4 . The segment numbering scheme shown will be referred to throughout the remainder of this report. A standard pulse-width modulated power processing unit incorporating a high voltage pulse starting circuit 5 was used in all testing. This was run with a standard laboratory $\mathrm{dc}$ power supply. Each individual anode segment could be connected to the positive side of the power supply through a hand operated switch allowing any combination of the segments to be connected at any time during experimentation. Individual Hall current probes were used to monitor the current through each segment and the readouts from these were fed to five channels of an eight channel strip chart recorder. These current monitors were calibrated prior to testing. The output from the current probe on segment 1 was also fed to a storage oscilloscope so that the current transient in this segment on startup could be observed. A digital multimeter was used to monitor the potential difference between the cathode and each segment.

Vacuum Faciliey, All tests were performed in a vacuum tank $1.5 \mathrm{~m}$ in diameter and $5 \mathrm{~m}$ in length. This facility was pumped by four oil diffusion pumps (30,000 lps) backed by a rotary blower and two mechanical roughing pumps. During arcjet operation, the pumps maintained the ambient pressure at approximately $0.65 \mathrm{~Pa}\left(5 \times 10^{-4}\right.$ torr). In all testing, a hydrogen/nitrogen mixture was used as the propellant and the mixture ratio was set at 2:1 to simulate fully decomposed hydrazine. Mass flow controllers of the thermal conductivity type were used in the propellant flow system and these were calibrated in-situ prior to the start of testing.

In the preliminary testing performed for this report, a mass flow rate of $5.0 \times 10^{-5} \mathrm{~kg} / \mathrm{sec}$ was used. This flow rate corresponds to high end of the pressure range expected in a typical blowdown propellant system. The high end was chosen to optimize the startups and flow stabilization in this device. A current of 10 amps was used and the typical power level in the experiments was about $1.1 \mathrm{~kW}$. This operating point in a baseline thruster (solid anode) would produce an Isp of about $425 \mathrm{sec}$ and $0.2 \mathrm{~N}$ of thrust with an efficiency of $35 \%$.

\section{RESULTS AND DISCUSSION}

Initial Burn-In and Testing. Because of the fragility of the anode and insulator segments, long experimental runs were not anticipated so the arcjet was first assembled with only the first anode segment and a freshly tipped cathode. This unit was run in a small vacuum bell jar, described elsewhere, ${ }^{7}$ for an extended period of time. After some initial instability, typical of arcjet behavior early in burn-in sequences, stable steady-state operation was attained. A highly luminous region was clearly visible at the constrictor exit. The attachment zone, however, did not appear to be evenly distributed about the constrictor and the plume was not symmetric along the axis of the constrictor. The arcjet voltage climbed rapidly to the 100 volt level indicating that the arc did extend from the cathode to seat at the end of the constrictor, a condition commonly known as "high mode." The voltage and chamber pressure decreased with time $\mathrm{e}^{4}$ and it was obvious upon disassembly that the crosssectional area of the constrictor had increased. The unit was then reassembled with the "burned-in" cathode, and the entire segmented nozzle, including a new first anode segment.

General Observations. Because of the small size of the anode and insulator segments, and the heat load typically dissipated in the anode (typically 100-150 watts for $1 \mathrm{~kW}$ class devices), it was expected that the unit would approach thermal equilibrium rapidly and that long experimental runs would not be possible. During operation, the segments did heat very rapidly but runs of up to four minutes were possible. In many of the tests, periods of time from 5 seconds to 1 minute were necessary before stable, steady-state operation was obtained. In this time the arc would frequently go out and then reignite. Some sparking was observed and the plume during this period was generally misshapen. When allowed to run through this period, however, stable operation was normally obtained with a fully expanded plume and smooth, uninterrupted current traces on all readouts attached to the various anode segments. Voltage fluctuations on startup in arcjet testing and have been ascribed to motion of the cathode attachment spot before a fixed, steady state is attained. ${ }^{7}$ In long runs under constant conditions, noise was typically observed on the current traces after about two minutes of operation. It is believed that this was due to propellant leaks around the segments caused by differential expansion as the end of the thruster, and especially the clamping flanges, approached thermal equilibrium. It should be noted that in some of the tests, stable operation was achieved almost instantly and that the current voltage characteristics were very similar to those obtained in tests of similar thrusters with single solid anodes with the same critical dimensions. A photograph of the thruster in operation with all of the segments connected is shown in Figure 5.

Starting Phenomena. Previous experiments have suggested that the arc discharge initiates upstream of the constrictor and rapidly moves to seat in the diverging portion of the nozzle. To confirm this 
hypothesis, the arcjet was started with all of the anode switches closed (i.e., all segments at anode potential). Oscilloscope records of the current transient to segment 1 showed that all of the current flowed through this segment for about $25 \mathrm{~ms}$ when the discharge was initiated before being forced to the diverging section (anode segments 2-5). In steady state operation, no current flowed through this segment. A typical oscilloscope trace of the transient is shown in Figure 6.

\section{Current Distribution and Current-Voltage} Characteristics. A series of tests were conducted to 1.) determine the current distribution across the nozzle, 2.) determine the voltage-current characteristics and 3.) determine how these changed as the arc attachment was forced to different regions of the nozzle. In most of the tests, the arc was started with all of the segments connected to the positive side of the power supply. The arcjet was allowed to run in this configuration until stable operation was obtained. This configuration most nearly resembles normal arcjet operation with a single solid anode insert. Current traces from a test in which this configuration was used are shown in Figure 7(a). From this it can be seen that no current returned through the first segment after startup and that, initially, a majority $(65-70 \%)$ of the current flows through the second and third segments. As the steady state condition is approached, however, the current redistributes slightly. A bar graph showing typical steady state current distribution is shown in Figure 7(b). This test was representative of most of the data taken. Typical operating voltage levels in this configuration ranged between 106 and 115 volts. There were instances in which the current distribution was more skewed toward the downstream segments. The cause of this is not clearly understood at present.

Tests in which the switches were opened in sequence starting with segment 1 were run and strip chart recorder data from one of these are shown in Figure 8(a). The data are also given in tabular form. From the data it can be seen that when the second segment is isolated, most of the current it carried goes to the next downstream segment. When the third segment was switched out, however, the current redistributed fairly evenly between the remaining two segments. Very litule hysteresis was observed as the sequence was reversed (i.e., segments reconnected). Throughout this experiment, the arcjet thruster ran very stably. In the configuration in which all of the current was forced to the segment furthest downstream, the are voltage was nearly identical to that observed in the case in which all of the segments were connected. From the potential drops observed between the cathode and the four upstream (isolated) segments, a rough indication of the voltage gradient across the nozzle can be obtained. This is shown in Figure 8(b). The data are averaged from all of the tests run in this configuration and the voltage measurements are plotted at the center of each segment. The average potential difference observed between the cathode and segment 1, was about 39 volts. A correction factor must be applied to the floating potential data to obtain the plasma potential. ${ }^{16}$ Assuming that the electron temperature is between 0.5 and $1.0 \mathrm{eV}, 17,18$ this factor drops the potential difference by only 2.5 to 5 volts. The magnitude of this potential difference indicates that only between 30 and 40 percent of the total power is dissipated in the constrictor region of the arcjet. Thus, a significant amount of energy addition occurs in the divergent section of the nozzle. Further testing, including measurements of thrust and structural heating, will be necessary to fully understand the effects of the energy addition mechanisms on arcjet performance. These findings, however, agree with recent experiments in which nozzle divergent geometries were found important in determining the position and characteristics of the anode attachment zone and, arcjet performance. ${ }^{15}$

A similar series of tests was performed to assess the effect of forcing the attachment to the upstream regions of the nozzle. In these tests, the anode was once again started with all of the segments connected. The segments were then switched out in sequence starting with segment 5 . This test was run a number of times to examine repeatability. A significant variation was observed in the current redistribution pattern when segment 5 was isolated. In early testing, most of the current flowing through this segment relocated in segments 2 and 3 with current flowing through segment 4 decreasing somewhat $(-20 \%)$. In later tests, the current from segment 5 appeared entirely on segment 4 . The remainder of the sequence was quite repeatable, however. When both segment 4 and segment 5 were isolated, the current redistributed fairly evenly across segments 2 and 3 . No significant current was observed through segment 1 until all of the other segments were isolated. The variation in behavior noted is not well understood at present. It is postulated that as the current is forced to attach in higher pressure regions of the anode, there is a higher likelihood that the attachment occurs in narrow zones or in spot mode rather than in a diffuse fashion across the entire conducting surface. Post-test analysis, described in the next section, showed that damage indicative of spot mode attachment had occurred on the upstream segments.

The voltage measurements followed a trend similar to that observed in the current measurements. Two modes were observed when segment 5 was isolated. In one, the potential difference between the cathode and this segment remained constant as the switch was opened (i.e., equal to that observed between the cathode and the other segments). This occurred when the current from this segment was 
observed to redeposit in segment 4 . In the other, the potential drop was 6-15 volts less than that observed across the other segments. This occurred when a large part of the current from segment 5 was distributed to segments 2 and 3 when segment 5 was isolated.

In all tests in which segments 4 and 5 were isolated, the potential drops observed were about 15 volts less than those between the connected segments and the cathode. The floating potential on these segments can be corrected to obtain the plasma potential as previously discussed. The difference between the plasma potential and that measured on the connected segments should, as a first order approximation, be equivalent to the anode fall voltage. Thus, it appears that in normal operation the anode fall voltage is between 10 and 20 volts. When segment 3 was switched out no change in its potential was observed. However, when all the current was forced to segment 1 , a very large change in operating mode was observed. In this case, the voltage drop between this segment and the cathode went up to approximately 120 volts (from 115 volts). The potential difference between the other segments and the cathode, however, dropped to 70-75 volts. This is shown in Fig. 9. Thus, it appears that when the current is forced to this segment (into the high pressure region) there is a significant increase in the anode fall voltage. As in the case of the energy addition mechanism, further testing of this unit, particularly on a thrust stand so that efficiency measurements can be obtained, will be necessary before this conclusion can be reached with certainty.

Post-Test Segment Analysis. Disassembly and inspection showed that segments 4 and 5 had very small spots where melting had occurred near the interface between the boron nitride and the tungsten. This damage was minimal and likely occurred at startup. Segment 3 had slightly more damage in this area and there were some small balls of tungsten on the segments inner surface that resembled those seen at the constrictor exit in other tests. 7,13 Aside from these, however, the surface was very clean with no evidence of localized melting. This was not the case for segment 2. This segment sustained damage in the form of localized melting and a molten droplet extended out to contact the boron nitride insulator on the downstream side of this segment. Continuity checks during the test indicated that there was no contact between this segment and segment 3. A scanning electron microscope (SEM) photograph of this segment is shown in Figure 10. Localized melting was also observed on the downstream surface of segment 1 (the segment comprising the converging section and throat of the nozzle). It is likely that the damage to these segments was caused by spot anode attachment during startup and when the arc current was forced to flow through these segments. The boron nitride insulators held up fairly well through the testing. While most of them had developed large cracks, they did not come apart until they were removed from the thruster, so it did not appear they had failed in their function during the experiment. All showed signs of some chipping, or loss of material, near the nozzle edges and this was more pronounced on the upstream insulators.

\section{CONCLUDING REMARKS}

A segmented anode/nozzle was fabricated and tested in a low power ( $1 \mathrm{~kW}$ class) arcjet thruster in order to study the current distribution and other phenomena in the attachment region. The critical dimensions of the nozzle matched those of solid nozzles commonly used in previous arcjet testing. The anode was designed so that current could be collected across any combination of the segments. The current through each segment was monitored, as was the potential between the cathode and each of the segments. The starting transient on the first segment (comprising the converging side of the nozzle and the constrictor) was also studied.

The starting transient measurements showed that the discharge initiated upstream on the first segment and then moved rapidly to the diverging section of the nozzle. With all of the segments connected to the positive side of the power supply, no current was observed in the upstream segment after the brief initial $(\sim 25 \mathrm{~ms})$ starting transient. In this configuration, the current attached diffuscly across all of the segments in the diverging side of the nozzle.

By isolating the upstream segments (i.e., forcing all of the current to attach in the last downstream segment) floating potential measurements were obtained and these provided a rough approximation of the voltage gradient across the arc column. These measurements showed that more than 50 percent of the energy input to the device occurs in the diverging section of the nozzle. Further experimentation, including measurements of both thrust and structural heating, will be necessary to gain a full understanding of the energy partitioning in this region.

By isolating the downstream segments and monitoring the floating potential, a rough approximation of the anode fall voltage was obtained. These preliminary measurements indicated that when the arc is allowed to seat in the diverging section, the anode fall voltage is between 10 to 20 volts. When forced to the high pressure segment, however, this appeared to increase by at least a factor of two. Further measurements of both device efficiency and 
structural heating will be necessary to confirm these conclusions about the anode fall zone. Post-test analysis of the segments did show evidence of melting and spot attachments in the upstream region.

\section{ACKNOWLEDGEMENTS}

The authors wish to express appreciation to Mr. Charles K. Smalley for his efforts in machining the nozzle segments used in the experiments described in this report.

\section{REFERENCES}

1. Hardy, T. L. and Curran, F. M., "Low Power dc Arcjet Operation with Hydrogen/Nitrogen/Ammonia Mixtures," AIAA Paper 87-1948, June 1987 (NASA TM-89876).

2. Knowles, S. C. , Smith, W. W., Curran, F. M., and Haag, T. W., "Performance Characterization of a Low Power Hydrazine Arcjet," AIAA Paper 87-1057, May 1987.

3. Knowles, S. K., "Arcjet Thruster Research and Technology," Phase I, Final Report, 87-R1175, Rocket Research Co., Redmond, WA September 1987, (NASA CR-182107).

4. Knowles, S. K., "Arcjet Thruster Research and Technology," Phase II, Rocket Research Co., Redmond, WA, (NASA CR-182276, to be published).

5. Gruber, R. P., "Power Electronics for a $1 \mathrm{~kW}$ Arcjet Thruster," AIAA Paper 86-1057, June 1986, (NASA TM-87340).

6. Sarmiento, C. J. and Gruber, R. P., "Low Power Arcjet Thruster Pulse Ignition," AIAA Paper 87-1951, July 1987, (NASA TM100123).

7. Curran, F. M. and Haag, T. W., "An Extended Life and Performance Test of a Low Power Arcjet," AIAA Paper 88-3106, July 1988, (NASA TM-100942).

8. Knowles, S. K. and Yano, S., "Engineering Model Low Power Arcjet System Development," presented at the 1989 JANNAF Mecting, Cleveland, OH, May 1989.

9. Yano, S. and Knowles, S. K., "Simulated Flight Qualification Test of an Engineering Model Arcjet System," presented at the 1989 JANNAF Meeting, Cleveland, OH, May 1989.
10. Zana, L. M. "Langmuir Probe Surveys of an Arcjet Exhaust," AIAA Paper No. 87-1950, July 1987 (NASA TM-89924).

11. Carney, L. M. and Sankovic, J., " The Effects of Arcjet Thruster Operating Condition and Constrictor Geometry on the Plasma Plume," AIAA Paper No. 89-2723, July 1989, (NASA TM-102248).

12. Carney, L. M., "Evaluation of the Communications Impact of a Low Power Arcjet Thruster," AIAA Paper 88-3105, July 1988, (NASA TM-100926).

13. Curran, F. M. and Haag, T. W., "Arcjet Component Conditions Through a Multistart Test," AIAA Paper 87-1060, May 1987, (NASA TM-89857).

14. Curran, F. M., Haag, T. W., and Raquet, J. F., "Arcjet Cathode Phenomena," presented at the 1989 JANNAF Meeting, Cleveland, OH, May 1989, (NASA TM-102099).

15. Curran, F. M., Sovie, A. J. and Haag, T. W., "Arcjet Nozzle Design Impacts," presented at the 1989 JANNAF Meeting, Cleveland, $\mathrm{OH}$, May 1989, (NASA TM-102050).

16. Chen, F. F ,"Electric Probes," in Plasma Diagnostic Techniques. Huddleston, R. H., and Leonard, S. C., eds. Academic Press, New York, 1965, pg 178.

17. Van Camp, W. M., et al, "Analysis of an Arcjet Exhaust," NASA CR-54102, McDonnell Aircraft Corp., December 1964.

18. Fox, R. L., "Spectrophotometric Observations of Hydrogen Arcjets," Developments in Applied Spectroscopy, Vol. 3, Proceedings of the 14th Annual Mid-America Spectroscopy Symposium," Chicago, IL; 1963, Plenum Press, New York, 1964. 


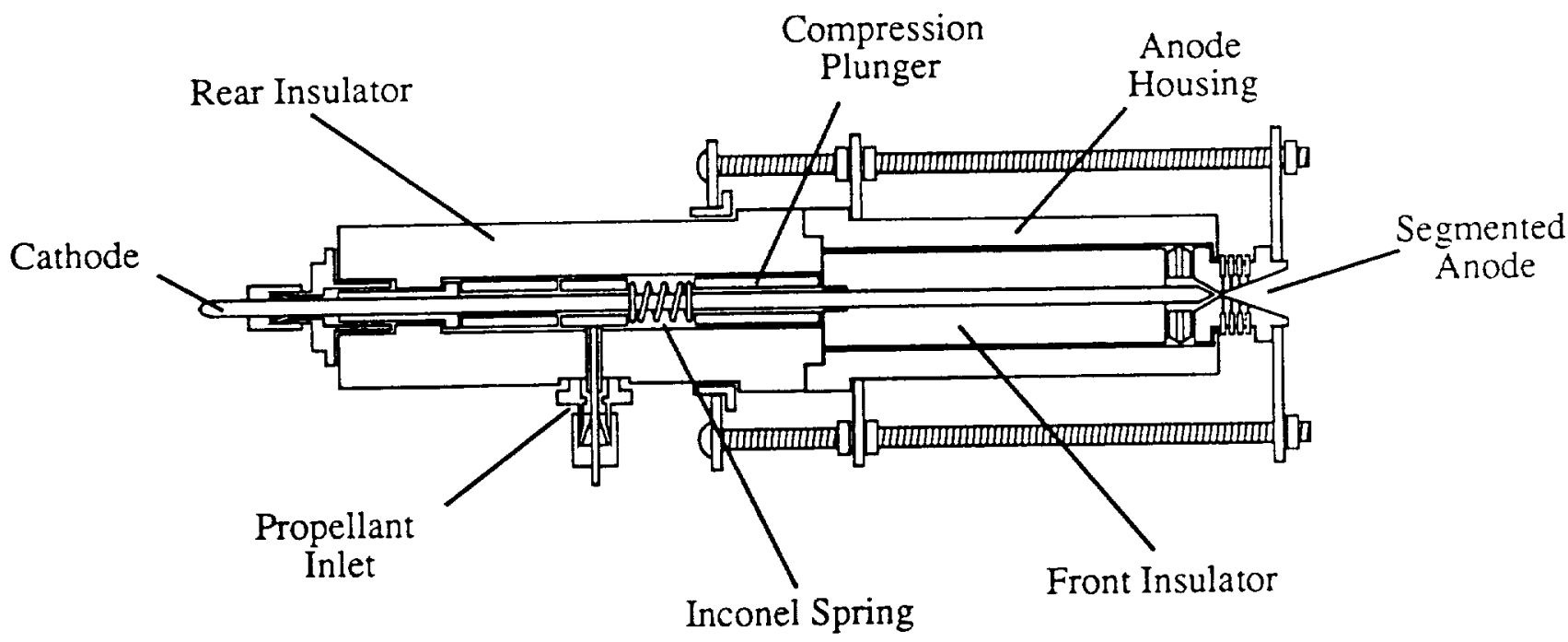

Figure 1. Cross-sectional schematic of the arcjet thruster.

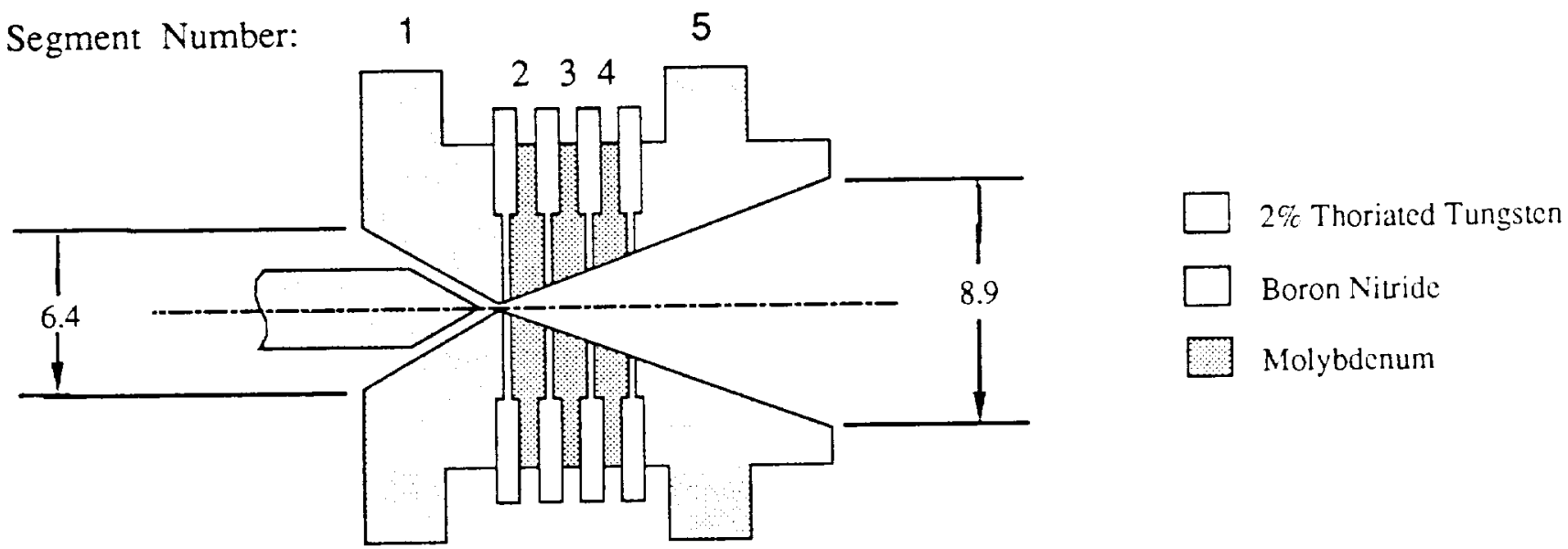

a) Cross-sectional schematic of segmented anode/nozzle.

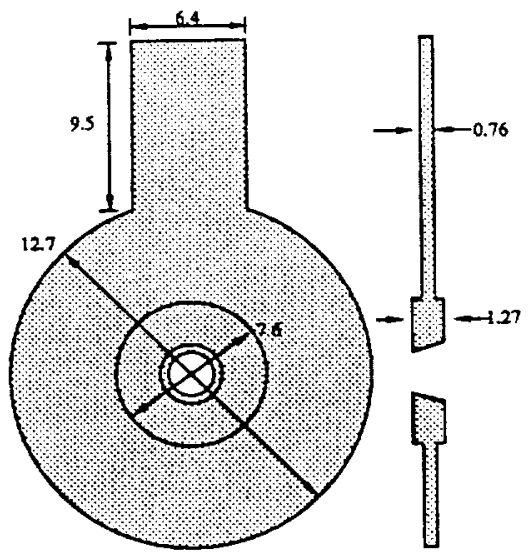

b) Molybdenum anode segment.

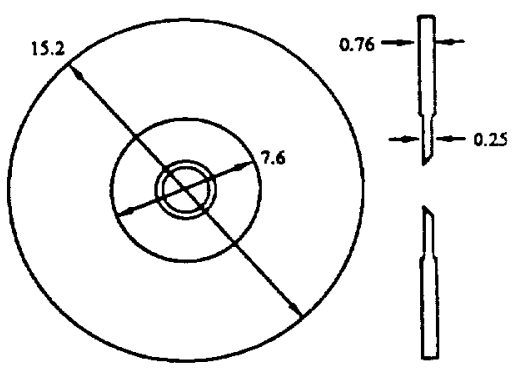

c) Boron nitride spacer.

Figure 2. Segmented anode/nozzle schematics.

(all dimensions in $\mathrm{mm}$ ) 


\section{ORIGINAL PAGE}

BLACK AND WHITE PHOTOGRAPH

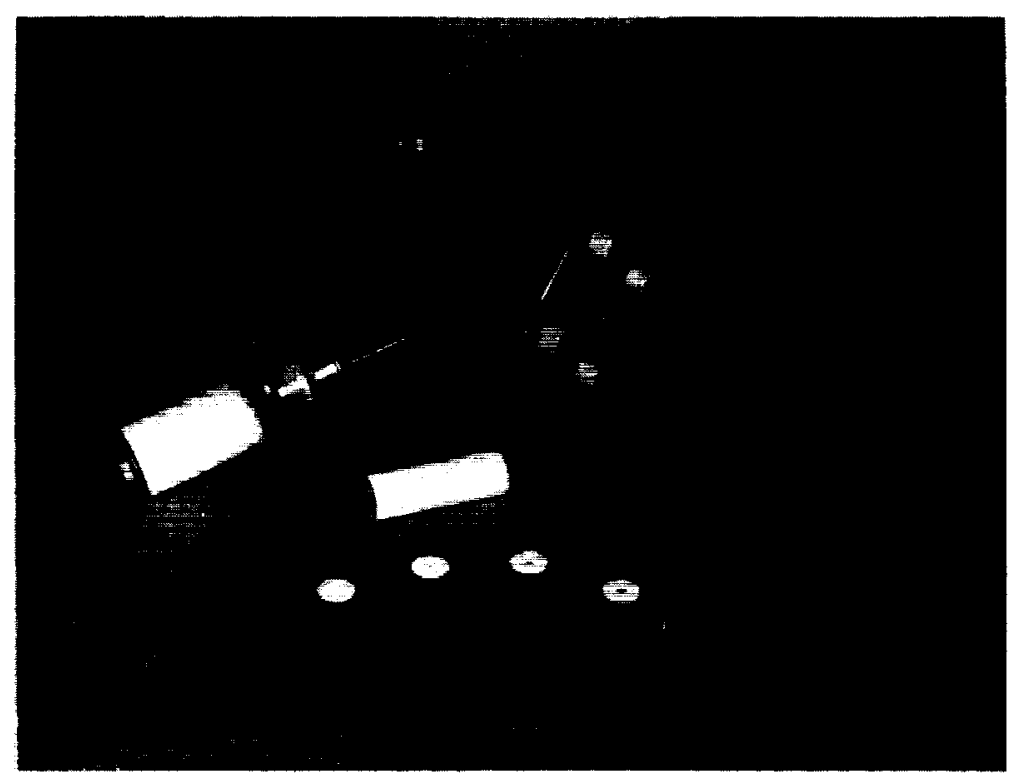

a) Unassembled components.

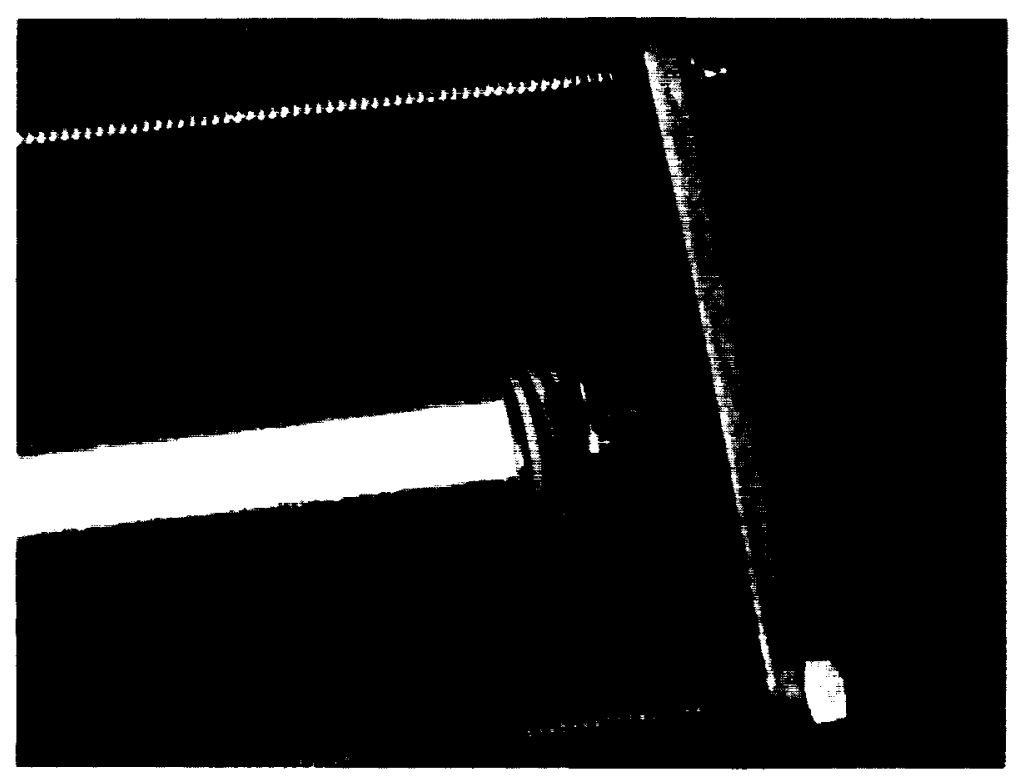

b) Assembled nozzle.

Figure 3. Segmented anode arcjet. 


\section{ORIGINAL PAGE IS OF POOR QUALITY}

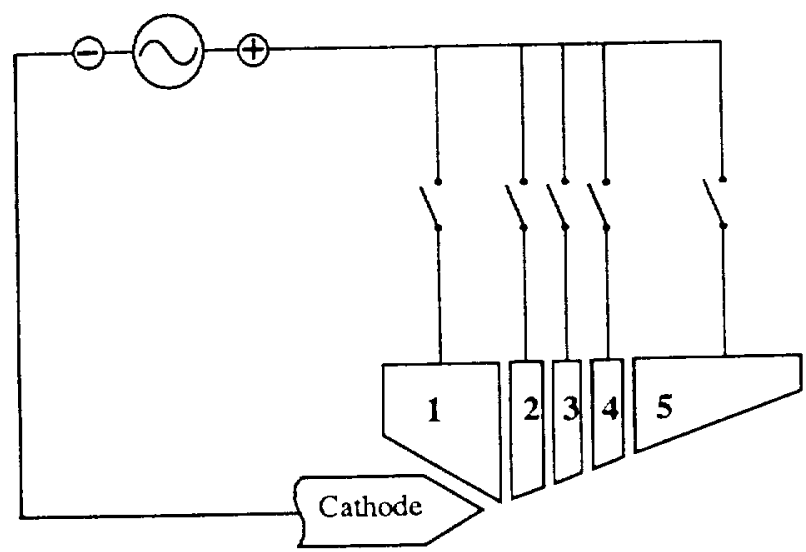

Figure 4. Simplified diagram of electrical configuration.

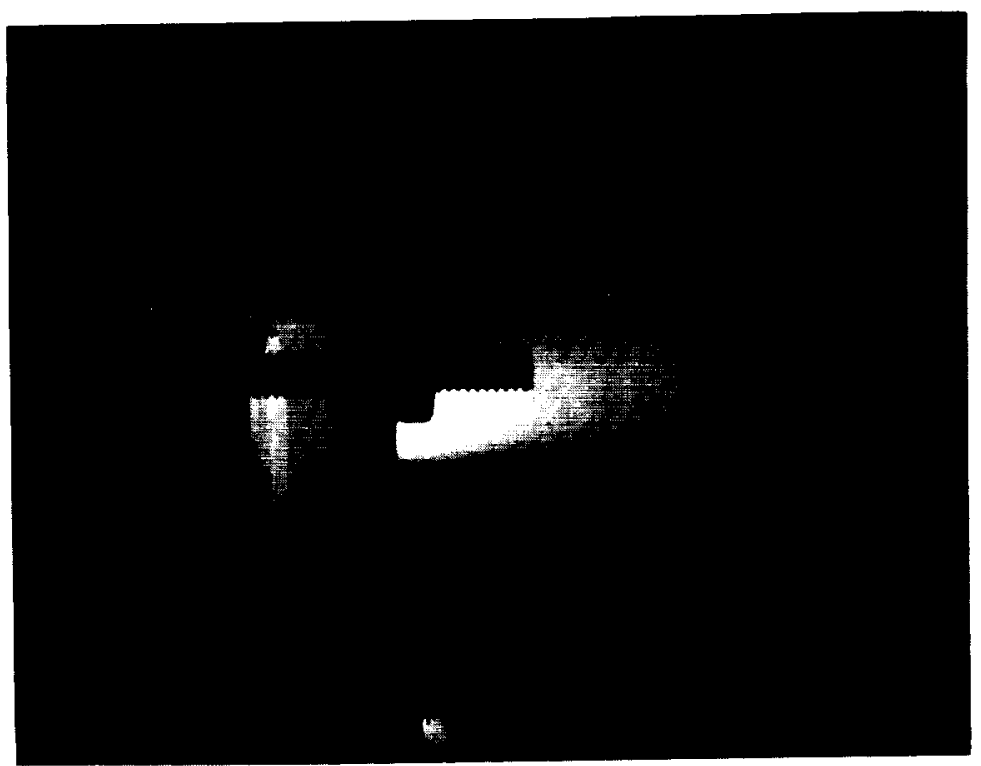

Figure 5. Arcjet in operation. 


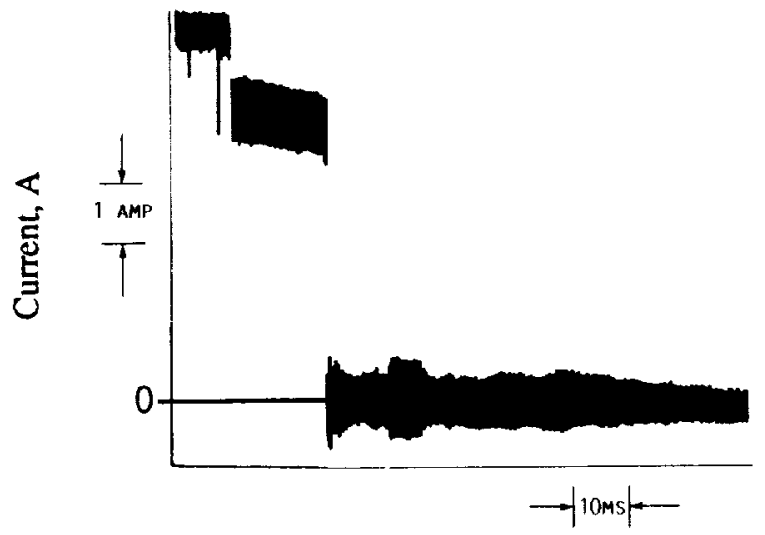

Figure 6. Current transient at startup (segment 1).
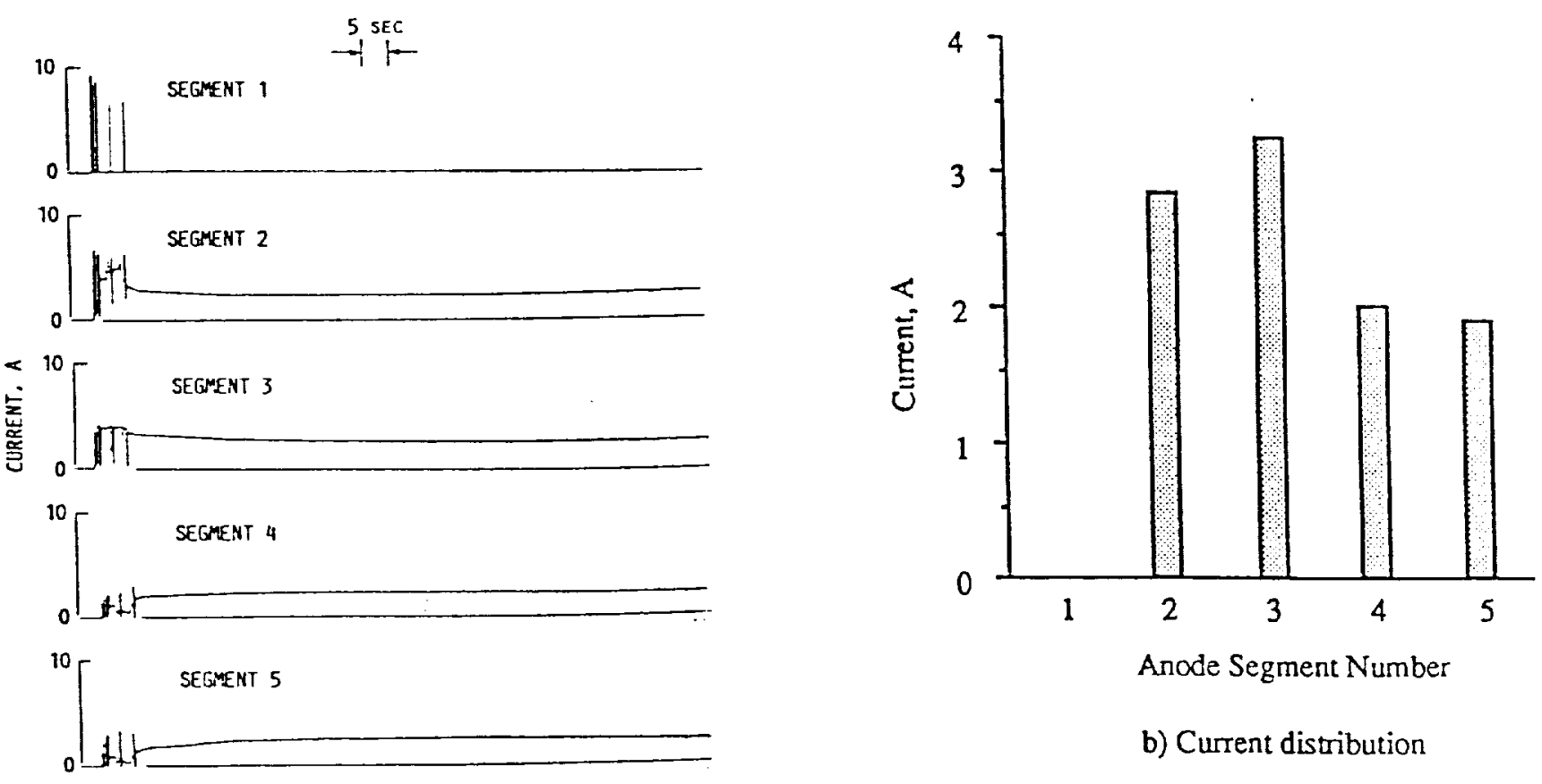

a) Strip chart record of current traces.

Figure 7. Current distribution at anode - all segments connected. 


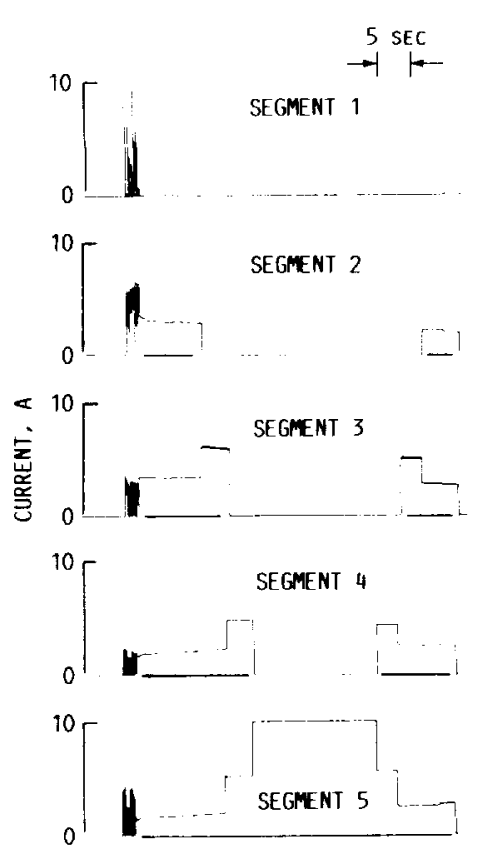

\begin{tabular}{|r|r|r|r|r|r|r|r|r|r|}
\hline \multicolumn{3}{|c|}{ SWITCHES (1 -- closed; 0 -- open) } & \multicolumn{5}{|c|}{ CURRENT (A) -segment number } \\
\hline S1 & S2 & S3 & S4 & S5 & 1 & 2 & 3 & 4 & \multicolumn{1}{|c|}{5} \\
\hline 0 & 1 & 1 & 1 & 1 & 0 & 3.0 & 3.0 & 2.0 & 2.0 \\
0 & 0 & 1 & 1 & 1 & 0 & 0 & 6.0 & 2.0 & 2.0 \\
0 & 0 & 0 & 1 & 1 & 0 & 0 & 0 & 4.8 & 5.2 \\
0 & 0 & 0 & 0 & 1 & 0 & 0 & 0 & 0 & 10.0 \\
0 & 0 & 0 & 1 & 1 & 0 & 0 & 0 & 4.2 & 5.8 \\
0 & 0 & 1 & 1 & 1 & 0 & 0 & 5.6 & 2.2 & 2.2 \\
0 & 1 & 1 & 1 & 1 & 0 & 2.3 & 2.9 & 2.6 & 2.1 \\
& & & & & & & & & \\
\hline
\end{tabular}

a) Strip chart record of current traces and data in tabular form.

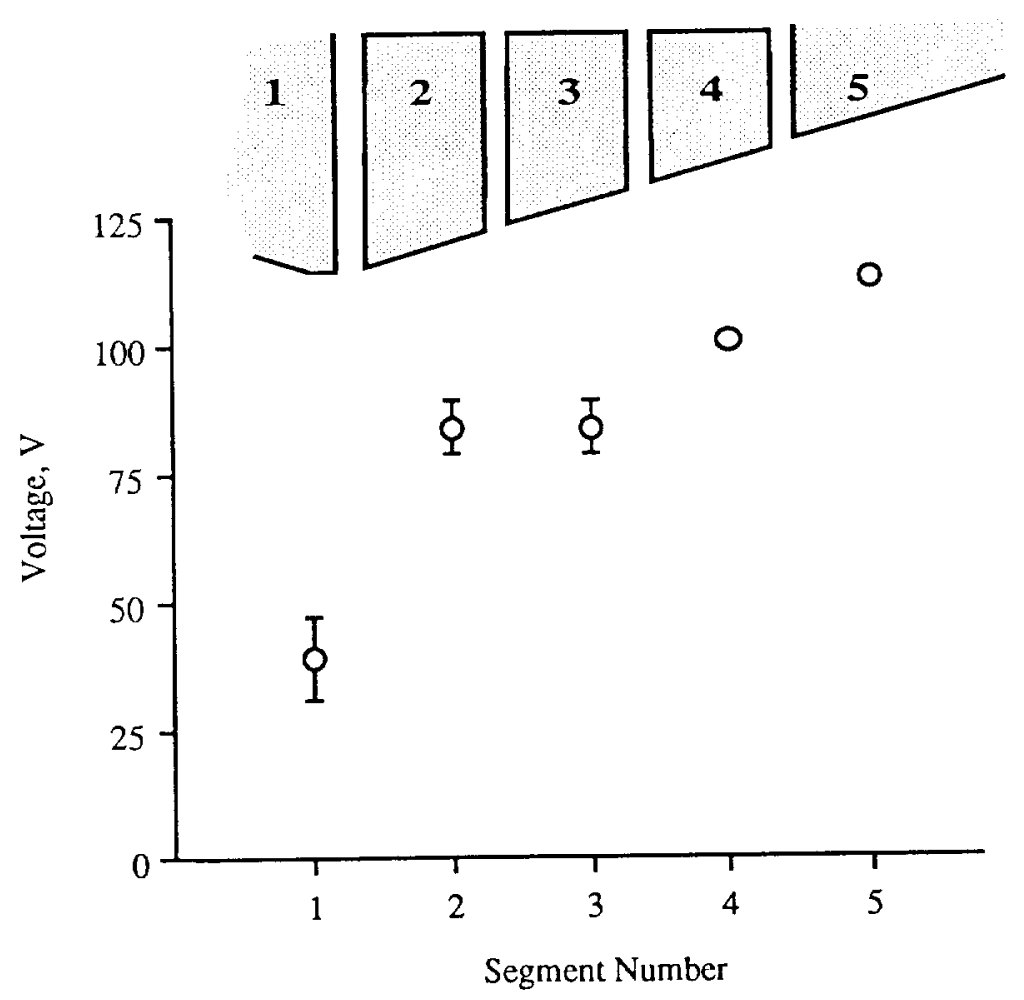

b) Floating potential difference versus anode segment number (segment 5 only connected)

Figure 8. Data from tests in which upstream segments were isolated. 


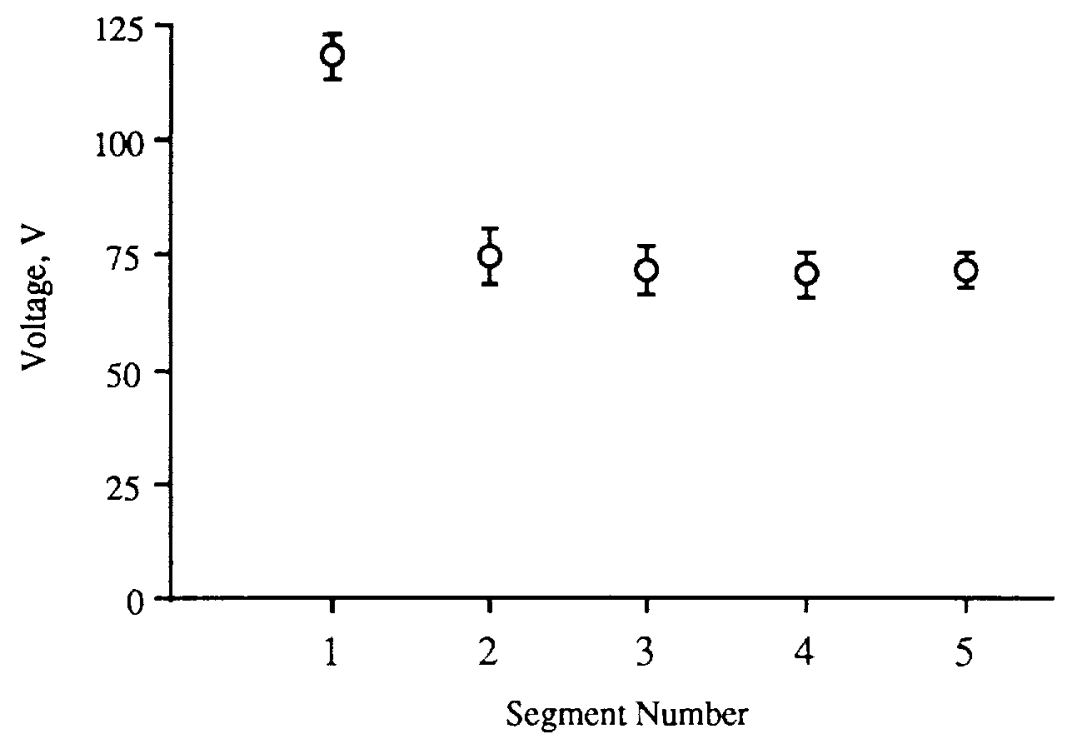

Figure 9. Floating potential data (Segment 1 only conducting).

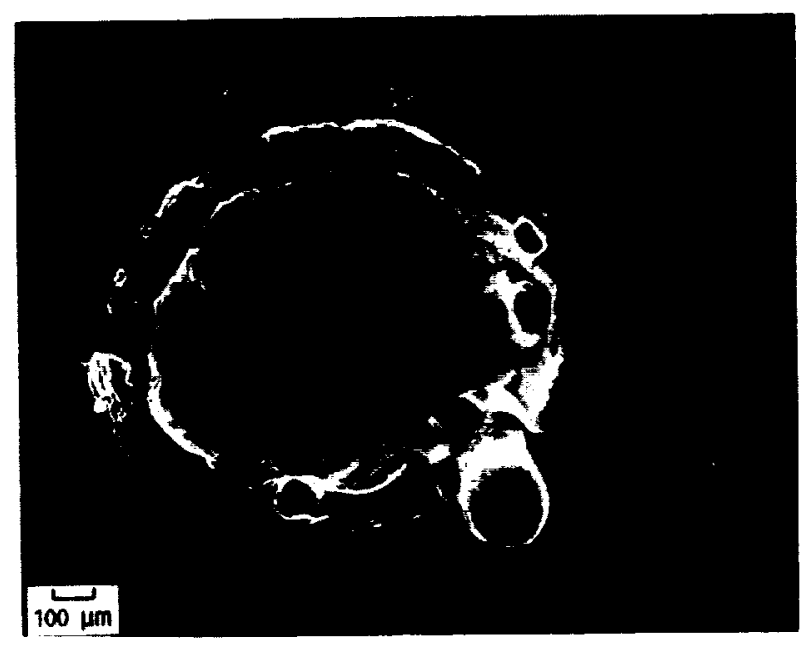

Figure 10. SEM photograph of downstream side of segment 2. (post-test). 


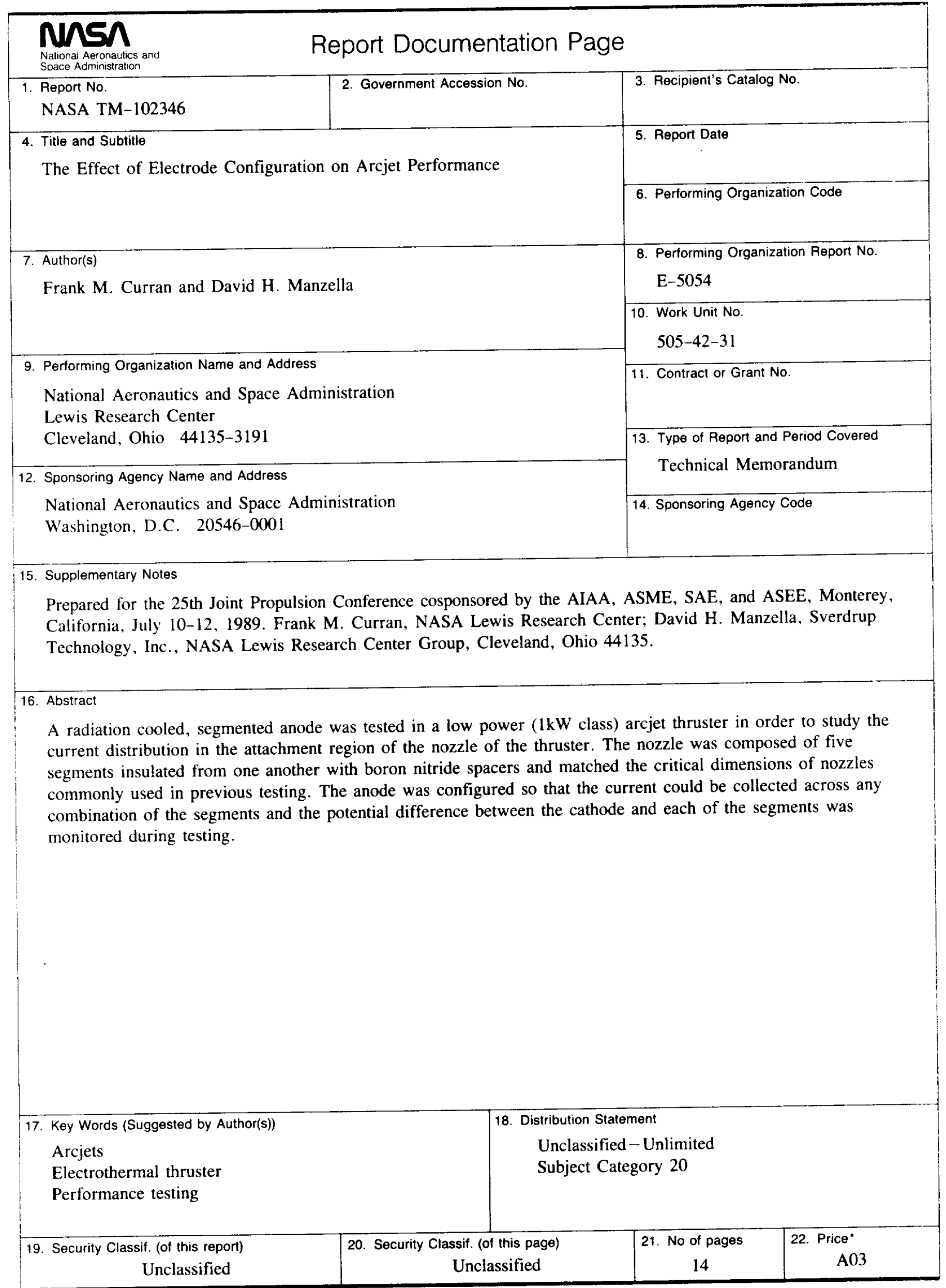


